\title{
Solubility and Tie Line Data for Ternary System of (water + phenol + isobutyl acetate) at $T=308.2 \mathrm{k}$
}

\author{
Milad Sangashekan ${ }^{1}$ and Hosein Ghanazadeh Gilani ${ }^{2}$
}

\begin{abstract}
This study demonstrates experimental solubility and tie-line data for the (water + phenol + isobutyl acetate) system at $T=$ $308.2 \mathrm{~K}$ and atmospheric pressure. This ternary system exhibits type- 2 behavior of LLE. To evaluate the extracting capability of the solvent, distribution coefficients and separation factors were calculated. The consistency of the experimental data was determined through the Othmer-Tobias and Bachman equations. The experimental data were correlated using the NRTL and UNIQUAC models, and binary interaction parameters were obtained. The average root mean square deviation values between the experimental and calculated data show the capability of these models.
\end{abstract}

Keywords - Liquid-liquid equilibrium, NRTL, Phenol, ternary system

\section{INTRODUCTION}

L IQUID-liquid equilibrium (LLE) data are needed for

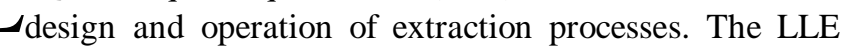
studies of ternary systems have been the subject of much attention in recent years.

Phenols are similar to alcohols but form stronger hydrogen bonds. Thus, they are more soluble in water than are alcohols and have higher boiling points. Phenol (phenylic acid) is a white, poisonous, crystalline solid at room temperature that melts at $41^{\circ} \mathrm{C}$. It is a widely used chemical in the manufacture of plastics or related materials, detergents, and drugs [1]-[3]. Also, it has many important applications for the production of phenolic resins in various industries. Phenol forms a binary azeotrope with water at $9.2 \mathrm{wt} \%$ of phenol, which is hard to separate by distillation. Moreover, the removal of phenol and phenolic compounds from wastewater has taken on great environmental interest over the last years [4], [5]. Therefore, recovery of phenolic compounds from aqueous solution using liquid-liquid extraction method is industrially and economically important [6].

Precise LLE data are needed in the evaluation of industrial units for solvent extraction processes. Some researchers have

Milad Sangashekan ${ }^{1}$, was with Department of Chemical Engineering, University of Guilan, 41335 Rasht, Iran (corresponding author's phone: ; e-mail: (+98) 9111537884, milad.sangashekan@ gmail.com ).

Hosein Ghanadazadeh Gilani ${ }^{2}$, is with Department of Chemical Engineering, University of Guilan, 41335 Rasht, Iran (e-mail: hggilani@guilan.ac.ir). been reported about solubility and equilibrium for the aqueous solutions of phenol with various organic solvents [7], [8]. Many solvents have been tested, and the phase equilibrium data of the related systems are presented in the literature. Mainly, alcohols, carbonate [9], alkyl carbonates [10], ketones [11], esters [12], [13], aliphatic, and aromatic hydrocarbons [14]-[16] have been used for extraction of phenol from water.

More LLE data for the ternary aqueous mixture of phenol with organic solvents recently have been reported by authors of this paper [17]. The organic solvents were 1-octanol, 2ethyl-1-hexanol, and cyclohexanone. In this research, isobutyl acetate (IBA) was chosen as an organic solvent for recovery of phenol from water at $\mathrm{T}=308.2, \mathrm{~K}$ and the phase compositions were measured.

In order to evaluate the extracting ability of the solvent for the separation of phenol from water, distribution coefficients and separation factors were determined from the tie-line data. The experimental tie-line data were correlated to test consistency with the Othmer-Tobias [18] and Bachman [19] equations. The experimental LLE data were correlated with the non-random two-liquid (NRTL) [20] and UNIQUAC [21] models and the values of the interaction parameters were obtained.

\section{II.EXPERIMENTAL}

\section{A. Materials}

The phenol and isobutyl acetate with stated mass fraction purities higher than 0.99 were purchased from Chem-lab and Merck, respectively. Deionised water was used throughout all experiments. All materials were used as received without any further purification. Some measured physical properties for the chemicals used in this study along with the literature values are listed in Table 1.

\section{B. Apparatus and procedure}

Refractive indices and densities of the pure liquids were measured at $\mathrm{T}=298.2 \mathrm{~K}$ using an Abbe Refractometer (model CETI, \pm 0.0002 ) and a DA210 density meter (Kyoto electronic, $\pm 0.05 \mathrm{~kg} . \mathrm{m}-3$ ), respectively. All weighting was carried out with an electronic analytical balance (model HR$200, \pm 0.0001 \mathrm{~g})$. 
The solubility curves were determined by the cloud point method in an equilibrium glass cell. The temperature of the cell was controlled by a water jacket and maintained with a digital thermometer (Lutron TM-917, $\pm 0.1 \mathrm{~K}$ ). At each system, the third component was progressively added using a microburet. The end-points were determined by observing the turbidity. All the measurements were repeated at least three times. The average of these readings was taken for the component compositions. The uncertainty in the mass fraction of the solubility data was estimated to be better than \pm 0.0001 . For the tie-line data measurements, a $250 \mathrm{~cm} 3$ glass cell connected to a thermostat that controlled temperature was used. The equilibrium data were determined by preparing the ternary mixture of known compositions. This mixture was agitated vigorously for at least $4 \mathrm{~h}$, and then left to settle for 5 $\mathrm{h}$ for complete phase separation. When the equilibrium was attained, samples of both phases were carefully analysed to determine their compositions.

TABLE I

Source, Purity, ReFractive IndeX (N), AND Density $(P)$ OF The Pure COMPONENTS AT $T=298.2 \mathrm{~K}$

\begin{tabular}{|c|c|c|c|c|}
\hline \multirow[t]{2}{*}{ component } & \multicolumn{2}{|l|}{$n$} & \multicolumn{2}{|c|}{$\rho /\left(\mathrm{kg} \cdot \mathrm{m}^{-\mathrm{z}}\right)$} \\
\hline & Exp. & Lit. & Exp. & Lit. \\
\hline Phenol & $1.5395^{\mathrm{b}}$ & $1.5395[7]^{\mathrm{b}}$ & & $1.3456^{\mathrm{c}}$ \\
\hline isobutyl acetate & 1.3456 & $1.3456[20]$ & 1.3456 & $1.3456[21]^{\mathrm{a}}$ \\
\hline Water & 1.3456 & $1.3456[19]$ & 1.3456 & $1.3456[19]$ \\
\hline
\end{tabular}

TABLE II

EQUATIONS For REFRACTIVE INDEX (N) As A FunCTION OF PHENOL AND

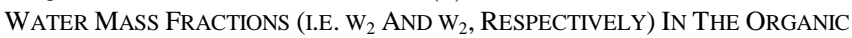
AND AQUEOUS PHASES AT T $=308.2 \mathrm{~K}^{\mathrm{A}}$

\begin{tabular}{lll}
\hline \hline & Equation & $R^{2}$ \\
\hline & $T=308.2$ & \\
phenol $_{(\text {org })}$ & $n=0.1490 w_{2}+1.3840$ & 0.9995 \\
phenol $_{(\mathrm{aq})}$ & $n=0.1662 w_{2}+1.3318$ & 0.9959 \\
Water $_{(\mathrm{aq})}$ & $n=0.1989 w_{1}+1.5287$ & 0.9908 \\
\hline${ }^{\mathrm{a}} \mathrm{Stand}$
\end{tabular}

${ }^{\mathrm{a}}$ Standard uncertainties u are $\mathrm{u}(\mathrm{T})=0.1 \mathrm{~K}, \mathrm{u}(\mathrm{n})=0.0001$, and $\mathrm{u}(\mathrm{w})=0.0001$

Details of the analysis have been previously reported in [22], [23]. In this paper, water content of the organic layer was measured by the Karl-Fisher method [24] using Metrohm-870 KF Titrino plus Karl-Fisher titrator. Concentration analyses of water and phenol were carried out for the aqueous phase using refractive index measurements. The refractive indices of the prepared standard samples lying on the binodal curves were measured used for building standard curves. Equations for refractive index (n) as a function of phenol mass fraction $\left(w_{2}\right)$ in both the phases, the mass fractions of water in the aqueous phase $\left(w_{1}\right)$ at $\mathrm{T}=$ $308.2 \mathrm{~K}$ are given in Table 2. The estimated uncertainty of all measured compositions is better than \pm 0.0001 . The uncertainty of the tie-line compositions were estimated according to the procedure suggested by Taylor and Kuyatt [25].

\section{RESULT AND DISCUSSION}

\section{A. Experimental LLE data}

Equilibrium composition for the system (water + phenol + IBA) in the temperature of $308.2 \mathrm{~K}$ and atmospheric pressure is given in Table 3 . The solubility curves for the investigated system is shown $T=308.2$ in Figure 1 .

\section{TABLE III}

SOLUBILITY CURVE DATA In MASS Fractions $\left(\boldsymbol{W}_{i}\right)$ For \{ WATER (1) + PHENOL (2) + IBA (3) $\}$ At $T=308.2 \mathrm{~K}^{\text {a }}$

\begin{tabular}{ccc}
\hline \hline$w_{I}($ water $)$ & $w_{2}($ phenol $)$ & $w_{3}(\mathrm{IBA})$ \\
\hline 0.0243 & 0.0000 & 0.9757 \\
0.0275 & 0.0982 & 0.8743 \\
0.0363 & 0.1946 & 0.7691 \\
0.0439 & 0.2863 & 0.6698 \\
0.0520 & 0.3787 & 0.5693 \\
0.0606 & 0.4690 & 0.4704 \\
0.0783 & 0.5496 & 0.3721 \\
0.1058 & 0.6201 & 0.2741 \\
0.1474 & 0.6812 & 0.1714 \\
0.2061 & 0.7146 & 0.0793 \\
0.3189 & 0.6811 & 0.0000 \\
0.9873 & 0.0000 & 0.0127 \\
0.9792 & 0.0157 & 0.0051 \\
0.9658 & 0.0309 & 0.0033 \\
0.9511 & 0.0469 & 0.0020 \\
0.9380 & 0.0607 & 0.0013 \\
0.9260 & 0.0735 & 0.0005 \\
0.9079 & 0.0921 & 0.0000 \\
\hline \hline
\end{tabular}

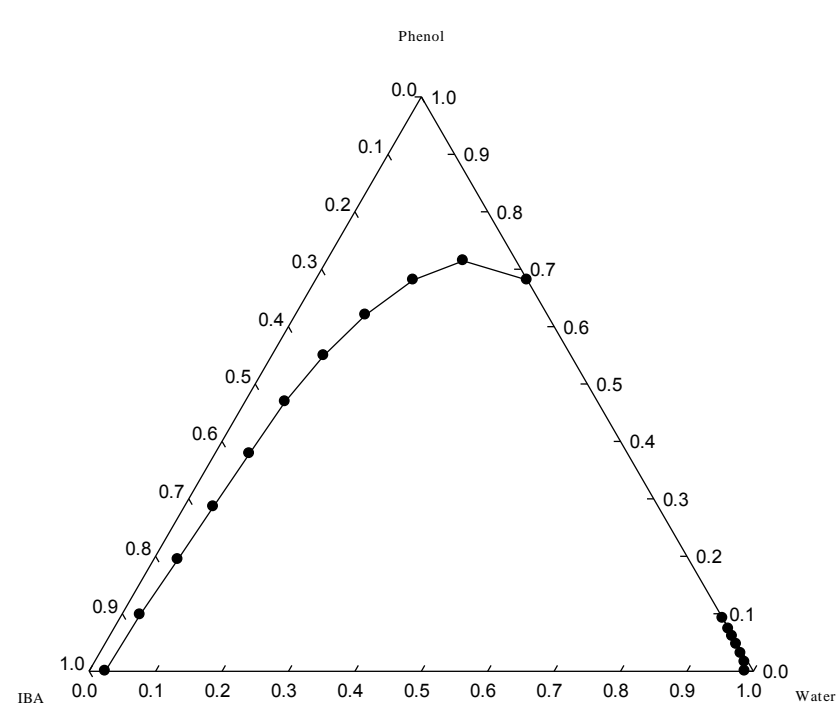

Fig.1. Solubility curve for the [water (1) + phenol (2) + IBA (3)] system at $T=308.2 \mathrm{~K}$

The experimental tie-line data for the ternary system at $T=$ $308.2 \mathrm{k}$ are listed in Table 4. The LLE diagram is also shown in Figures 2. Since the (phenol + IBA) mixture is the only liquid pair that is completely miscible, this ternary system 
behaves as type-2 LLE [26], and therefore, the phase diagrams show no plait points.

TABLE IV

EXPERIMENTAL TIE-LINE DATA IN MASS FRACTIONS $\left(w_{i}\right)$ AND REFRACTIVE INDICES (n) FoR \{WATER (1) + PHENOL (2) + IBA (3) $\}$ At $T=$ $308.2 \mathrm{~K}^{\mathrm{a}}$

\begin{tabular}{llll}
\hline \hline \multicolumn{4}{c}{ Aqueous phase } \\
\hline $\mathrm{w}_{1}($ water $)$ & $\mathrm{w}_{2}$ (phenol) & $\mathrm{w}_{3}$ (solvent) & $\mathrm{n}$ \\
\hline 0.9884 & 0.0018 & 0.0098 & 1.3321 \\
0.9834 & 0.0078 & 0.0088 & 1.3331 \\
0.9774 & 0.0150 & 0.0076 & 1.3343 \\
0.9698 & 0.0241 & 0.0061 & 1.3358 \\
0.9633 & 0.0319 & 0.0048 & 1.3371 \\
0.9588 & 0.0373 & 0.0039 & 1.3380 \\
\hline \multicolumn{4}{c}{ Organic phase } \\
\hline $\mathrm{w}_{1}($ water $)$ & $\mathrm{w}_{2}($ phenol $)$ & $\mathrm{w}_{3}($ solvent $)$ & $\mathrm{n}$ \\
\hline 0.0332 & 0.1966 & 0.7702 & 1.4133 \\
0.0442 & 0.3174 & 0.6384 & 1.4313 \\
0.0526 & 0.4040 & 0.5434 & 1.4442 \\
0.0610 & 0.4664 & 0.4726 & 1.4535 \\
0.0717 & 0.5141 & 0.4142 & 1.4606 \\
0.0792 & 0.5510 & 0.3698 & 1.4661 \\
\hline \hline Standard uncertainties u are u(T) $=0.1 \mathrm{~K}, \mathrm{u}(\mathrm{n})=0.0001$, and $\mathrm{u}(\mathrm{w})=0.0001$.
\end{tabular}

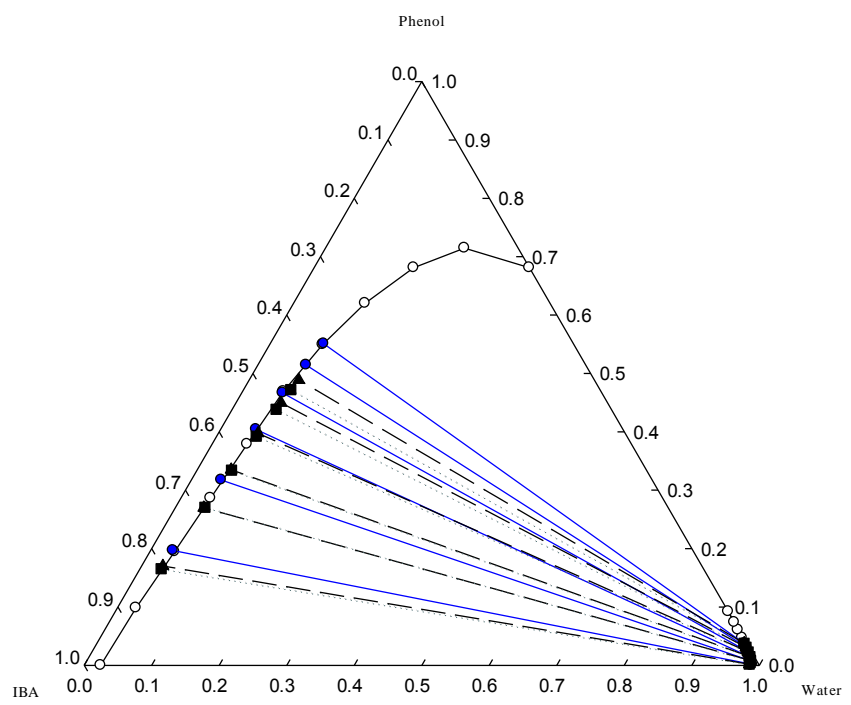

Fig. 2 Ternary diagram for the [water (1) + phenol (2) + IBA (3)]

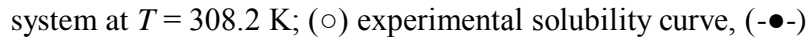
experimental tie-line data, (-- $\boldsymbol{\Delta}$--) calculated NRTL data, ( $\cdot \bullet \cdot \cdot)$ calculated UNIQUAC data.

\section{B. Distribution coefficient and separation factor}

In order to evaluate the extracting capability of IBA at each temperature for the separation of phenol from aqueous solutions, the separation factor $(S)$ was calculated. The separation factor is defined as the ratio of distribution coefficients of phenol $\left(D_{2}\right)$ to water $\left(D_{1}\right)$

$S=\frac{w_{23} / w_{21}}{w_{13} / w_{11}}=\frac{D_{2}}{D_{1}}$; where $w_{13}$, and $w_{23}$ are the mass fractions of water and phenol in the organic phase, respectively. $w_{11}$, and $w_{21}$ are the mass fractions of water and phenol in the aqueous phase, respectively] The distribution coefficients and separation factors for $\mathrm{T}=308.2 \mathrm{k}$ are given in Table 5.

TABLE V

Distribution CoEfFicients For WATER $\left(D_{1}\right)$ ANd Phenol $\left(D_{2}\right)$ AND SEPARATION FACTORS (S) At $T=308.2 \mathrm{~K}$.

\begin{tabular}{llc}
\hline \hline$D_{l}$ & $D_{2}$ & $S$ \\
\hline 0.0401 & 15.9640 & 398.1316 \\
0.0469 & 15.3731 & 327.7927 \\
0.0559 & 14.3093 & 256.0358 \\
0.0710 & 12.4854 & 175.7463 \\
0.0814 & 12.2559 & 150.5638 \\
0.0904 & 11.9272 & 131.9472 \\
\hline \hline
\end{tabular}

The variation of experimental separation factor of phenol as a function of the mass fraction of the solute in aqueous phase $\left(w_{21}\right)$ is shown in Figure 3. For the investigated ternary system, the experimental results indicate that these solvent have high separation factor, thereby indicating the ability of the solvent to extract phenol from water.. In general, the average uncertainty for $\mathrm{S}$ was less than 0.05 .

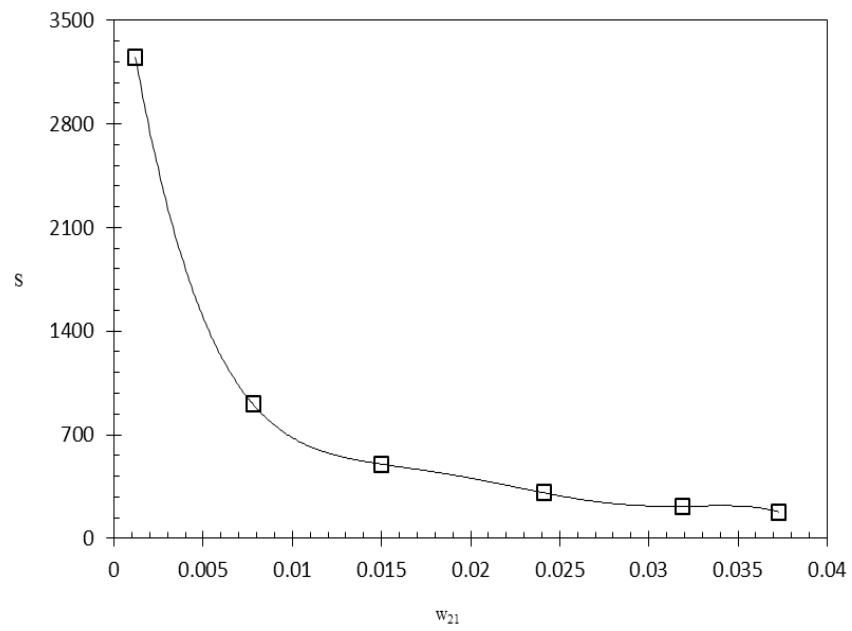

Fig. 3 Separation factor (S) plotted against the mass fraction of phenol in the aqueous phase at $T=308.2 \mathrm{k}$.

\section{Consistency of tie-line data}

The reliability of experimentally measured tie-line data can be determined by applying the Othmer-Tobias [18] (equation (1)) and Bachman [19] (equation (2)) correlation equation.

$$
\begin{aligned}
& \ln \left(\frac{1-w_{33}}{w_{33}}\right)=\mathrm{A}+\mathrm{B} \ln \left(\frac{1-\mathrm{w}_{11}}{\mathrm{w}_{11}}\right) \\
& w_{2 \mathrm{a}}=A^{v}+B^{f}\left(\frac{\mathrm{w}_{33}}{\mathrm{w}_{11}}\right)
\end{aligned}
$$

Where $w_{33}$ is mass fraction of solvent in the solvent-rich phase; A, B, A' and $\mathrm{B}^{\prime}$ are the parameters of the OthmerTobias and the Bachman correlations, respectively. These parameters are listed in Table 6 and shown in Figures 4 and 5 , respectively. The correlation factor $\left(\mathrm{R}^{2}\right)$, and the linearity of the plots indicates the degree of consistency the measured LLE results in this work. 
TABLE VI

OTHMER-TOBIAS AND BACHMAN EQUATIONS CONSTANTS AND THE CORRELATION FACTOR (R2) FOR THE \{WATER (1) + PHENOL (2) + IBA (3) System At $T=308.2 \mathrm{~K}$.

\begin{tabular}{|c|c|c|c|c|c|}
\hline \multicolumn{3}{|c|}{ Othmer-Tobias correlation } & \multicolumn{3}{|c|}{ Bachman correlation } \\
\hline A & $\mathrm{B}$ & $\mathrm{R}^{2}$ & $\mathrm{~A}^{\prime}$ & $\mathrm{B}^{\prime}$ & $\mathrm{R}^{2}$ \\
\hline 4.5766 & 1.2815 & 0.9886 & 0.0215 & 1.0148 & 0.9999 \\
\hline
\end{tabular}

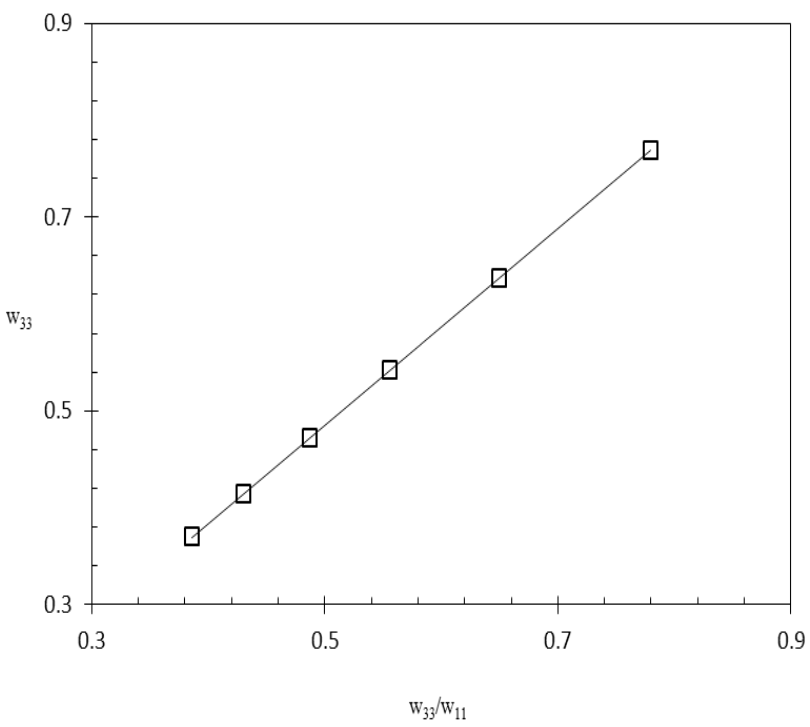

Fig. 6. Bachman plot for the $\{$ water (1) + phenol (2) + IBA (3) $\}$ system $T=308.2 \mathrm{~K}$

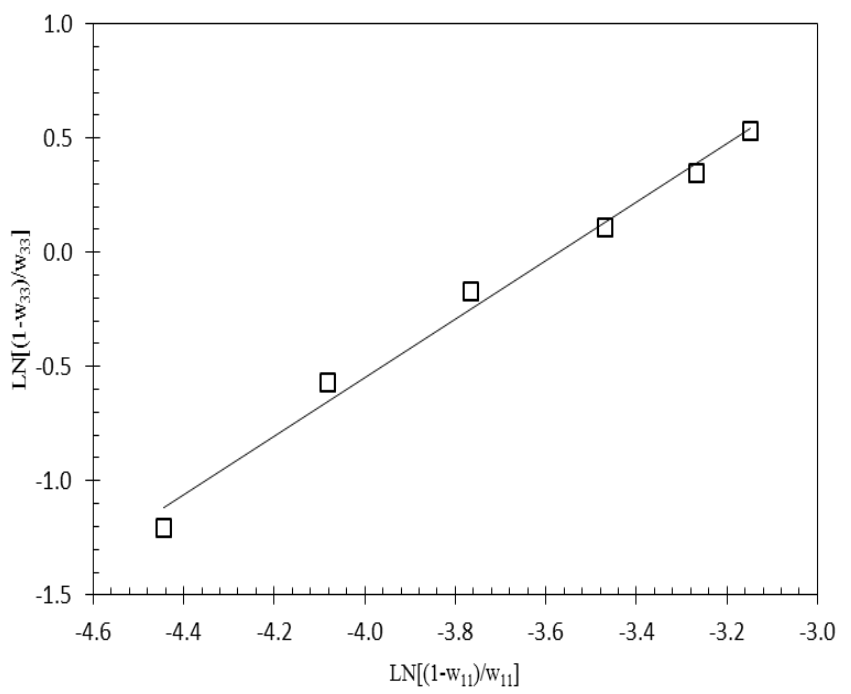

Fig. 7 Othmer-Tobias for the $\{$ water (1) + phenol (2) + IBA (3) $\}$ system at $T=308.2 \mathrm{~K}$.

The experimental tie-line data for each ternary system were Correlated using the NRTL [20] and the UNIQUAC [21] models. The calculated data for the ternary systems at $\mathrm{T}=$ $308.2 \mathrm{~K}$ are listed in Table 7.
TABLE VII

CALCUlated UNIQUAC AND NRTL TIE-Line VALUES IN MASS FRACTION

\begin{tabular}{|c|c|c|c|c|}
\hline \multicolumn{2}{|c|}{$\mathrm{w}_{1}$ (water) } & & \multicolumn{2}{|c|}{$\mathrm{w}_{2}$ (phenol) } \\
\hline NRTL & UNIQUAC & & NRTL & UNIQUAC \\
\hline & & Aqueous phase & & \\
\hline 0.9842 & 0.9839 & & 0.0020 & 0.0021 \\
\hline 0.9830 & 0.9829 & & 0.0082 & 0.0082 \\
\hline 0.9784 & 0.9785 & & 0.0148 & 0.0148 \\
\hline 0.9716 & 0.9718 & & 0.0231 & 0.0229 \\
\hline 0.9645 & 0.9647 & & 0.0311 & 0.0310 \\
\hline 0.9586 & 0.9585 & & 0.0377 & 0.0377 \\
\hline & & Organic phase & & \\
\hline 0.0391 & 0.0367 & & 0.1700 & 0.1655 \\
\hline 0.0456 & 0.0480 & & 0.2699 & 0.2709 \\
\hline 0.0561 & 0.0581 & & 0.3349 & 0.3344 \\
\hline 0.0690 & 0.0683 & & 0.3974 & 0.3924 \\
\hline 0.0778 & 0.0746 & & 0.4496 & 0.4384 \\
\hline 0.0830 & 0.0779 & & 0.4889 & 0.4721 \\
\hline
\end{tabular}

Figure 2 also compare the calculated tie-lines from the NRTL and UNIQUAC models with the experimental results. The values $r$ and $q$ (the UNIQUAC structural parameters) used for this ternary system were taken from reference [27] and are presented in Table 8. In the present work, the value of the non-randomness was fixed at 0.25 . The corresponding sets of binary interaction parameters were evaluated for each of the components over all of the tie-lines. The NRTL and UNIQUAC binary interaction parameters for the ternary systems of (water + phenol + IBA) at $\mathrm{T}=308.2 \mathrm{~K}$ are shown in Tables 9 and 10, respectively. The root-mean-square deviation (RMSD) value was calculated from the difference between the experimental and calculated mass fractions according to the following equation:

$$
\mathrm{RMSD}=\sqrt{\frac{\sum_{k=1}^{n} \Sigma_{j=1}^{n} \Sigma_{i=1}^{n}\left(w_{i j k}^{e x p}-w_{i j k}^{f a l}\right)^{2}}{6 n}}
$$

Where $n$ is the number of tie-lines, $w^{\exp }$ indicates the experimental mass fraction, $w^{\text {cal }}$ the calculated mass fraction, and subscript $\mathrm{i}$ indexes components, $\mathrm{j}$ indexes phases and $\mathrm{k}=$ $1,2, \ldots, \mathrm{n}$ (tie-lines).

TABLE VIII

The UNIQUAC Structural Parameters ( $r$ And $q$ ) For Pure Components [22].

\begin{tabular}{lcl}
\hline \hline components & $r$ & $q$ \\
\hline Isobutyl acetate & 4.8300 & 4.1900 \\
Phenol & 3.54647 & 2.71600 \\
Water & 0.92000 & 1.40000 \\
\hline \hline
\end{tabular}

The average root-mean-square deviations are presented in Tables 9 and 10 for NRTL and UNIQUAC models for (water + phenol + IBA). It can be seen that both models presented good agreement between the measured and calculated mass fractions for the studies system. 
TABLE IX

$\operatorname{NRTL}(\alpha=0.25)$ BINARY INTERACTION PARAMETERS $\left(b_{i j}\right.$ And $\left.b_{j i}\right)$ And RMSD VALUES FOR THE TERNARY SYSTEM.

\begin{tabular}{llll}
\hline \hline$i-j$ & $b_{i j} * / k$ & $b_{j i} / k$ & $R M S D \%$ \\
\hline & & & \\
$1-2$ & 2811.48 & 1620.47 & 3.48 \\
$1-3$ & 1930.48 & 1008.88 & \\
$2-3$ & 2288.05 & 2532.17 & \\
\hline \hline$b_{i j}=\left(\frac{\alpha_{i j}-x_{j i}}{a}\right)$ & & &
\end{tabular}

TABLE $X$

UNIQUAC BINARY INTERACTION PARAMETERS $\left(b_{i j}\right.$ And $\left.b_{j i}\right)$ And RMSD VALUES FOR THE TERNARY SYSTEM.

\begin{tabular}{|c|c|c|c|}
\hline$i-j$ & $b_{i j} * / k$ & $b_{j i} / k$ & $R M S D \%$ \\
\hline \multicolumn{4}{|c|}{$T=308.2$} \\
\hline $1-2$ & 793.04 & 2064.21 & 3.89 \\
\hline $1-3$ & -91.64 & 1168.60 & \\
\hline $2-3$ & 954.98 & 1393.39 & \\
\hline
\end{tabular}

\section{CONCLUSION}

Tie-line data for the (water + phenol + IBA) ternary system were obtained at $\mathrm{T}=308.2 \mathrm{~K}$. The ternary system exhibits type-2 behavior of the LLE. The consistency of tie-line data was verified by applying the Othmer-Tobias and Bachman equations. The linearity of the plots indicates the consistency of the experimental data. The separation factors and distribution coefficients for the organic solvent used in this work were calculated. The experimental results indicate that IBA has high separation factors, indicating the ability of this solvent to extract phenol from water. It can be concluded that it can be considered as reliable organic solvent for the extraction of phenol from aqueous solutions.

The UNIQUAC and NRTL $(\alpha=0.25)$ models were satisfactorily used to correlate the experimental data and to calculate the phase compositions of the mixtures studied. The corresponding optimized binary interaction parameters were also calculated. Both the models give relatively good results for the system investigated..

\section{ACKNOWLEDGMENT}

This work was supported financially by research grant from Hosein Ghanadzadeh Gilani from Guilan University.

\section{REFERENCES}

[1] M. Weber and M. Kleine-Boymann., "Ullmanńs Encyclopedia of Industrial Chemistry", (2004).

[2] S. Matar and Hatch, "L.F., Chemistry of Petrochemical Process", second ed., Gulf Professional Publishing, Hannover, (2001).

[3] J.G. Speight, "Chemical and Process Handbook, McGraw-Hill, New York", (2002)

[4] V. Dohnal and D. Fenclova, "Air-water partitioning and aqueous solubility of phenols", J. Chemical Engineering Data, 40, 478-483 (1995).
[5] R.T.P Pinto, L. Lintomen,,L.F Luz and M.R Wolf-Maciel "Strategies for recovering phenol from wastewater: thermodynamic evaluation and environmental concerns", Fluid Phase Equilibria, 228/229, 447-457 (2005).

[6] D.L Venter and I. Nieuwoudt,, "Liquid-Liquid Equilibria for Phenolic Compounds, Neutral Oils, and Nitrogen Bases at 313.15 K", J. Chemical Engineering Data, 46, 813-822 (2001).

[7] J.R.A González, E.A. M.E Soares. and A.G Medina, "Liquid-liquid equilibria for ternary systems of water-phenol and solvents: data and representation with models", Fluid Phase Equilibria, 26, 289-302 (1986).

[8] K. Scott, A. Adhamy and I.F McConvey.," Liquid-liquid equilibria of phenol, acetic acid, oxalic acid, and glyoxylic acid between water and 1decanol and tridecanol", J. Chemical Engineering Data, 37, 391-393 (1992).

[9] L.H Oliveira and M. Aznar, "(Liquid+liquid) equilibrium of \{water+phenol+(1-butanol, or 2-butanol, or tert-butanol)\} systems", $J$. Chemical Engineering, 42, 1379-1385 (2010).

[10]I.C. Hwang, and S.J. Park, "Liquid-liquid equilibria of ternary mixtures of dimethyl carbonate, diphenyl carbonate, phenol and water at $358.15 \mathrm{~K}$ ", Fluid Phase Equilibria, 301, 18-21 (2011).

[11] C.F. Yang,, Y. Qian, Y.B Jiang. and L.J Zhang," Liquid-liquid equilibria for the quaternary system methyl isobutyl ketone-water-phenolhydroquinone", Fluid Phase Equilibria, 258, 73-77 (2007).

[12]K.S. Narasimha, C.C. Reddy and K.S. Chari, "Solubility and Equilibrium Data of Phenol-Water-Isoamyl Acetate and Phenol-Water-Methyl Isobutyl Ketone Systems at $30^{\circ}$ C", J. Chemical Engineering Data, 7, 457-460 (1962).

[13] K.S. Narasimha, C.C. Reddy and K.S. Chari, "Solubility and Equilibrium Data of Phenol-Water-n-Butyl Acetate System at $30^{\circ}$ C", J. Chemical Engineering Data, 7, 340-344 (1962).

[14] A. Martin, M. Klauck, K. Taubert., A. Precht, R. Meinhardt and J. Schmelzer, "Vapor-Liquid Equilibria in Ternary Systems of Toluene or Octane + Phenols + Water", J. Chemical Engineering Data, 56, 733-740 (2011).

[15] A. Martin, M. Klauck, A. Grenner, R. Meinhardt,, D. Martin and J. Schmelzer," Liquid-Liquid(-Liquid) Equilibria in Ternary Systems of Aliphatic Hydrocarbons (Heptane or Octane) + Phenols + Water", $J$. Chemical Engineering Data, 56, 741-749 (2011).

[16] M. Mohsen-Nia anD I. Paikar, "Ternary and Quaternary Liquid + Liquid Equilibria for Systems of (Water + Toluene + m-Xylene + Phenol)", $J$. Chemical Engineering Data, 52, 180-183 (2007).

[17] H. Ghanadzadeh Gilani, A. Ghanadzadeh Gilani and M. Sangashekan, "Tie-line data for the aqueous solutions of phenol with organic solvents at $\mathrm{T}=298.2 \mathrm{~K}$ ", J. Chemical Thermodynamics, 58, 142-148 (2013).

[18] D.F. Othmer and P.F. Tobias, "The line correlation, Industrial and Engneering Chemistry", 34, 693-696 (1942).

[19] I. Bachman, "Tie Lines in Ternary Liquid Systems, Industrial and Engneering Chemistry", 12, 38-39 (1940).

[20]H. Renon and J.M. Prausnitz., "Local compositions in thermodynamic excess functions for liquid mixtures", American Institute of Chemical Engineers J., 14 135-144 (1968).

[21] D.S. Abrams and J.M. Prausnitz., "Statistical thermodynamics of liquidmixtures: New expression for excess Gibbs energy of partly or completely miscible systems", American Institute of Chemical Engineers J., 21, 116128 (1975).

[22] H. Ghanadzadeh Gilani, M. Golpour, and S.S.Ashraf, "Experimental and correlated tie-line data for aqueous mixtures of 2-butanol with 2-ethyl-1hexanol at various temperatures", Fluid Phase Equilibria, 310, 192-197 (2011).

[23] R. Munoz., J.B Monton, M.C Burguet, and J. de la Torre, "Phase equilibria in the ternary system isobutyl alcohol + isobutyl acetate +1 hexanol and the binary systems isobutyl alcohol +1 -hexanol, isobutyl acetate + 1-hexanol at 101.3 kPa", Fluid Phase Equilibria, 235, 64-71 (2005).

[24] E. Scholz, "Karl Fischer Titration", Springer Verlag, Heidelberg, (1984).

[25] B.N Taylor and C.E Kuyatt, "Guidelines for the Evaluation and Expression of Uncertainty in NIST Measurement Results Technical Note 1297 for NIST", MD, Gaithersburg, (1994).

[26] R.E Treybal, "Liquid Extraction", McGraw-Hill, New York, (1963).

[27] R. Wittig, J. Lohmann, and J. Gmehling,, "Vapor-Liquid Equilibria by UNIFAC Group Contribution. 6. Revision and Extension, Industrial and Engineering Chemistry Research", 42, 183-188 (2003). 